\title{
APROXIMAÇÕES CRÍTICAS SOBRE A FUNÇÃO DO DIREITO NO HORIZONTE DAS TENSÕES ENTRE MERCADO E SOCIEDADE: FRAGMENTOS DO PAPEL DO DIREITO PENAL ${ }^{1}$
}

EVALUATIVE APPROACHES TO THE FUNCTION OF LAW IN THE TENSIONS BETWEEN THE MARKET AND SOCIETY: FRAGMENTATION OF THE ROLE OF CRIMINAL LAW?

APROXIMACIONES CRÍTICAS SOBRE LA FUNCIÓN DEL DERECHO EN EL HORIZONTE DE LAS TENSIONES ENTRE MERCADO Y SOCIEDAD: ¿FRAGMENTOS DEL ROL DEL DERECHO PENAL?

\section{Rogério Gesta Leal²}

\section{Janriê Rodrigues Reck ${ }^{3}$}

1 Este artigo é fruto da pesquisa em nível de Pós-Doutoramento, em realização, junto à Universidade da Coruña, Galícia, Espanha, no âmbito do Grupo de Pesquisa Derecho Público Global, sob a coordenação do Prof. Dr. Jaime Rodriguez-Araña Muñoz.

2 Doutor em Direito. Professor Titular da Universidade de Santa Cruz do Sul - UNISC, do Programa de Doutorado e Mestrado em Direito. Professor da UNOESC, do Mestrado em Direito. Professor Colaborador do Mestrado em Direito da Fundação Escola Superior do Ministério Público do Estado do Rio Grande do Sul. Desembargador do Tribunal de Justiça do Estado do Rio Grande do Sul, junto à Quarta Câmara Criminal, cuja competência originária é julgar os crimes praticados por Prefeitos e Vereadores e os Crimes contra a Administração Pública. Coordenador do Grupo de Pesquisa Internacional sobre Patologias Corruptivas. Professor Convidado da Universidad da Coruña, Espanha; Uniminho, Portugal; Università Roma Trè, Roma; Universidad de Buenos Aires, Argentina. E-mail: rleal@unisc.br

3 Doutor em Direito. Professor do PPGD da UNISC, Brasil. Membro da Advocacia Geral da 
Resumo: O presente trabalho busca enfrentar o tema que envolve algumas insuficiências normativas e regulatórias das tensas relações entre Mercado e Sociedade, que geram conflitos por vezes hipercomplexos, a partir de abordagens no campo da Teoria do Direito e da Dogmática Jurídica, dando destaque exemplificativo para alguns âmbitos do Direito Penal Contemporâneo.

Palavras-chave: Sociedade de Riscos. Mercado. Sistemas Normativos.

Abstract: This work addresses issues involving some normative and regulatory shortcomings of the strained relations between Market and Society, which generate conflicts that are sometimes extremely complex. This debate takes place in the field of Theory of Law and Legal Dogmatic, highlighting some examples for some areas of Contemporary Criminal Law.

Keywords: Risk Society. Market. Regulatory Systems.

Resumen: El presente trabajo pretende analizar el tema que envuelve algunas insuficiencias normativas y regulatorias de las tensas relaciones entre Mercado y Sociedad, que generan conflictos algunas veces hipercomplejos, a partir de abordajes en el campo de la Teoría del Derecho y de la Dogmática Jurídica, dando destaque ejemplificativo a algunos ámbitos del Derecho Penal Contemporáneo.

Palabras clave: Sociedad de Riesgos. Mercado. Sistemas Normativos. 


\section{NOTAS INTRODUTÓRIAS}

Pretende-se neste texto tratar do tema que envolve as tensões relações entre o funcionamento do mercado capitalista contemporâneo (lato senso) e suas consequências no âmbito da exclusão social, decorrendo daí determinadas reações de delinquência e violência por parte de alguns grupos sociais.

Estes elementos todos juntos constituem combustão explosiva no que diz respeito às violações constantes a direitos e garantais individuais e sociais, assim como sentimento de insegurança e vitimização em setores sociais que (de)formam a opinião pública, configurando o que alguns sociólogos e juristas chamam de Sociedade de Riscos.

É preciso entender melhor tais fenômenos para que se consiga avaliar de forma crítica os limites e as possibilidades jurídicas do Direito à recomposição da ordem e da segurança de todos, em especial e de forma meramente exemplificativa (o que será aprofundado em outros estudos), as do Direito Penal contemporâneo em Sociedades de Riscos como a que se vive.

\section{CAPITALISMO E INSEGURANÇA SOCIAL: ALGUNS PARADIGMAS}

Há certa convergência entre os teóricos do capitalismo contemporâneo mais críticos que: "capitalism is a flawed system that, if its development is not constrained, it will lead to periodic deep depression and the perpetuation of poverty." ${ }^{4} \mathrm{E}$ isto por razões absolutamente empíricas mais do que normativas, basta se olhar para as múltiplas crises globais que ele tem causado nos últimos anos. De certa forma as chamadas crises financeiras que têm assolado países desenvolvidos e em desenvolvimento podem ser vistas como sistemáticas, nas quais estas ocorrências podem ser atribuídas como consequências do próprio capitalismo - notadamente em sua forma neoliberal ${ }^{5}$ -

União. E-mail: janriereck@ibest.com.br

4 BELLAMY, Foster and MAGDOFF, Fernand J. The Great Financial Crisis: Causes and Consequences. New York. Monthly Review Press, 2009, p.34.

5 Como diz Kotz: The neoliberal practice of capitalism aimed to work towards higher profits via risk taking, in terms of the housing bubble in the US; the financial institutions made mass amounts of money through risky mortgage selling and other such related trans- 
sem controle ou com controles de funcionamento deficitários.

Ao lado disto, ainda se tem a nítida percepção de Paul Hirst ao advertir para os ricos que a sociedade industrial tem produzido ao longo de sua expansão:

Industrial society has created many dangers of risks unknown in previous ages. The risks associated with global warming are one example. In the present era of industrialization, the nature of risk has undergone tremendous change. Earlier, there was no absence of risk. But these risks were natural dangers or hazards. There was earthquake, there was epidemic, there was famine and there were floods. But the risks in the modern society are created by our own social development and by the development of science and technology. Sometimes we fail to ascertain the risk involved in a particular aspect of technology. For instance, no onde quite knows what risks are involved in the production of genetically modified foods. ${ }^{6}$

É no âmbito deste capitalismo desenfreado (e sem centro algum) que vão se formatando ações e reações individuais, institucionais e sociais, por vezes ilícitas, mas geradoras de recursos financeiros exponenciais - está-se falando do narcotráfico, da lavagem de dinheiro, dos crimes cibernéticos, ambientais, contra o consumidor, etc. O problema é que o Estado contemporâneo geralmente não está preparado para tal enfrentamento, principalmente sob a perspectiva preventiva; quiçá em alguns momentos agentes estatais estão cooperando com aqueles ilícitos. ${ }^{7}$

É preciso ter em conta que governo e organizações criminosas, não raro, criam formas de convivência de instáveis equilíbrios, na medida em que as organizações criminosas ajustam suas ações e estratégias de acordo com as políticas públicas

actions. KOTZ, Martin D. The Financial and Economic Crisis of 2008: A Systemic Crisis of Neoliberal Capitalism. In: Review of Radical Political Economics. 41: 305. DOI: 10.1177/0486613409335093, p.18.

6 HIRST, Paul. THOMPOSON, Graham. Globalisation in Question. Cambridge: Polity, 2002, p. 38.

7 Como adverte Silva Sánchez, a comercialização de produtos ou a utilização de substâncias cujos possíveis efeitos nocivos são ainda desconhecidos, e em regra se manifestam depois de realizada a conduta, introduzem importantes fatores de incerteza na vida social. Isto faz com que surge a chamada multiplicação emocional do risco existente, pois cada vez mais pessoas introjetam que podem confiar cada vez menos gente e em circunstâncias cada vez mais excepcionais. SILVA SÀNCHEZ, Jesús-Maria. L'espansione del diritto penale. Aspetti della politica criminale nelle società industriali. Milano: Giuffrè-Quaderni di diritto penale comparato internazionale ed europeo, 2004. 
que visam Ihes enfrentar - muitas vezes contando com a colaboração do próprio Estado. É que as administrações públicas também coordenam suas políticas em função das percepções que têm de prioridades conjunturais e eleitoreiras. Disto decorre que Bailey e Taylor sustentam que: "When governments attempt to control or repress their activities, criminal groups employ various tools and instruments that might be grouped into three categories: evasion, corruption, and confrontation."

Neste quadro histórico e político a função do Estado - ao menos no Ocidente - tem sido muito mais a de garantir as condições ideais à expansão do livre mercado, inclusive para interferir o mínimo possível em suas oscilações cíclicas, até sob o argumento de que este Estado não tem condições de lançar mão das informações necessárias para compreender os sinais do mercado e de seu funcionamento - notadamente em razão da transnacionalidade operacional em que atua.

Por tais razões e para garantir o funcionamento deste modelo de mercado, o Estado (notadamente na ótica do neoliberalismo contemporâneo) deve criar mecanismos legais e instituições que protejam integralmente os direitos de propriedade e sua defesa, a partir da formatação de organizações (até policiais) adequadas para tanto, bem como garantindo a inviolabilidade da moeda e do câmbio. ${ }^{8}$ Em face disto, a teoria Keynesiana chegou a sustentar que o papel central do Estado diante de um mercado e uma economia como esta seria o de reduzir os efeitos perversos que criavam, para os fins de proteger aqueles que não se viam incluídos no modelo, e mais que isto, eram marginalizados por ele, justificando assim a experiência do Estado do Bem-Estar Social, por exemplo, que supostamente protegeria o emprego, os meios de sustento digno das pessoas e, ao fim e ao cabo, a própria Sociedade das instabilidades provocadas pelo laissez faire do livre mercado. ${ }^{9}$

O novo neoliberalismo agrega distintos argumentos para se autojustificar, como o de que as classes economicamente abastadas estão tendo preocupações

8 Ver o texto de DAHL, Robert and LINDBLOM, Charles. Politics, Economy and Welfare: Planning and Politico-Economic Systems Resolved into Basic Social Processes. New York: Harper, 1953.

9 Ver o texto de HAYES, Mark. The Economics of Keynes: A New Guide to The General Theory. Northampton, MA, 2010. 
e ações de solidariedade inclusiva em face dos segmentos sociais mais pobres e marginalizados, e o próprio mercado, sensibilizado com a desventura de alguns, cria projetos de qualificação e absorção (inclusive ideológica) daqueles sujeitos que se amoldam ao perfil por ele desejado, e também por isto, estratégias como a retirada ou redução da presença do Estado na regulação da economia, a explosão dos processos de privatização e o enfraquecimento político dos Estados do BemEstar, sem sombra de dúvidas, estimularam continentes a aderirem às políticas do neoliberalismo (voluntária ou coercitivamente).

Algumas questões que se colocam aqui dizem respeito a se tentar responder como e por que este neoliberalismo tem se tornado tão amplamente aceito e como isto tem se espalhado em todo o globo.

Os movimentos na direção do projeto neoliberal originam-se a partir das novas elites hegemônicas do capitalismo mundial e são possíveis em face, dentre outras, das políticas de desregulamentação da ordem econômica e das relações de trabalho, como já advertia Bourdieu. ${ }^{10}$

Neste sentido, um dos mais salientes exemplos do que se está afirmando tem sido o chamado Acordo Multilateral de Investimento ${ }^{11}$, de meados dos anos 10 BOURDIEU, Pierre. The Essence of Neoliberalism. In: https://mondediplo. com/1998/12/08bourdieu, acesso em 18/01/2016. O autor começa este texto já de forma provocativa dizendo: As the dominant discourse would have it, the economic world is a pure and perfect order, implacably unrolling the logic of its predictable consequences, and prompt to repress all violations by the sanctions that it inflicts, either automatically or - more unusually - through the intermediary of its armed extensions, the International Monetary Fund (IMF) and the Organization for Economic Cooperation and Development (OECD) and the policies they impose: reducing labour costs, reducing public expenditures and making work more flexible. Is the dominant discourse right? What if, in reality, this economic order were no more than the implementation of a utopia - the utopia of neoliberalism - thus converted into apolitical problem? One that, with the aid of the economic theory that it proclaims, succeeds in conceiving of itself as the scientific description of reality?

11 Os 29 países mais ricos do mundo, tendo à frente os membros do G7, começaram, em 1995, secretamente (no sentido estrito deste termo, ou seja, no sentido militar) a negociar o Acordo Multilateral de Investimentos (AMI). A negociação foi realizada discretamente entre os governos dos países membros da Organização para a Cooperação e Desenvolvimento Econômico (OCDE), sem o conhecimento dos cidadãos dos respectivos países nem de seus representantes parlamentares. Havia a vontade manifesta de manter a opinião pública na ignorância. Nos primeiros meses de 1997 , cerca de $90 \%$ do projeto já tinha a forma que poderia vir a ser definitiva. Ver neste sentido os textos de PERRONE-MOISÉS, Cláudia. Direito ao Desenvolvimento e Investimento Internacional. São Paulo: Ed. Oliveira Mendes, 1998; THORSTENSEN, Vera. OMC - Organização Mundial do Comércio: as regras do comércio internacional e a Nova Rodada de Negociações Multilaterais. São Paulo: Aduaneiras, 2001. 
1990, instituído para proteger corporações estrangeiras/multinacionais do controle dos Estados Nações, isto porque um dos fundamentos do poder do neoliberalismo advém do fato de que ele serve aos interesses destas corporações, de seus acionistas que são atraídos pelos grandes lucros de curto prazo às expensas de suas viabilidades a longo prazo, bem como grupos de mercado e proeminentes agentes políticos que invariavelmente provêm das mesmas elites. Em outras palavras, este neoliberalismo se torna atrativo para o público referido em face de que um de seus objetivos principais é garantir a competição empresarial a partir de determinados paradigmas de inclusão e exclusão - institucional e social -, ao mesmo tempo em que institui níveis inéditos de liberdade pessoal, dando-Ihes a oportunidade de criar empresas e adquirir, na falta de termo melhor, o que se pode chamar de uma vida de sonhos (american dream).

Sob esta perspectiva é interessante a reflexão de Gray, fazendo a distinção entre o que chama de bom e mau capitalismo, sendo que o primeiro é fundado em nações democráticas, cujos custos sociais que as empresas respondem habilitamnas como verdadeiras instituições sociais, sem comprometer a coesão da ordem política e econômica em que operam. Estes custos sociais são financiados pela via dos altos tributos que estas empresas pagam nestas sociedades.

Por outro lado, na perspectiva do mau capitalismo, há companhias que nascem no mercado livre, já no modelo neoliberal, com poucas obrigações sociais, consequentemente, pagam poucos tributos, e quase independem da sociedade em que se inserem, até em face de suas características especulativas e financeiras. Por óbvio que as companhias que nascem comprometidas com as sociedades em que atuam têm lucros e rendimentos potencialmente muito menores em face daquelas que já nascem em mercados livres e não têm vínculos sociais mais orgânicos e compromissados, e isto tudo vai gerando culturas de mercado menos humanitárias em termos de desenvolvimento social. ${ }^{12}$

Diga-se, por outra via, que esta liberdade de ação que o neoliberalismo assegura à iniciativa privada/corporativa permita o apoderamento destes sujeitos para os fins de levar ao máximo as suas potencialidades empreendedoras, a perseguição de determinadas ambições e o aprimoramento de suas condições

12 GRAY, John. False Dawn: The Delusions of Global Capitalism. London: Granta, 1998. 
comportamentais nos espaços que ocupam. ${ }^{13}$ Só há um detalhe aqui, tais benesses são alcançáveis somente por aqueles que têm condições de autonomia, independência e materiais para escolher tais possibilidades.

Por isto Silva Sánchez esclarece que:

Nella società postindustriale, migrazioni, disoccupazioni, conflitti culturali, problemi di articolazione interna determinano una situazione di coesistenza che genera conflitti interindividuali con episodi più o meno espliciti di violenza, in questo contesto, il primo fattore di rischio percepito è costituito dall'Altro. ${ }^{14}$

E quem é este OUTRO?

Ma I'Altro non è più un singolo individuo, ma è il grupo, la moltitudine, la società nel suo insieme: sono infatti intere città ad essere considerate "insicure", non i singoli cittadini che abitano in quel contesto. ${ }^{15}$

Economistas neoliberais chegaram a prever a morte do modelo social democrata da Europa desde que as taxas de desemprego na América do Norte e Inglaterra começaram a cair nos anos 1990 por conta, dizem eles, das políticas econômicas de extrema liberação dos mercados, enquanto que na Europa elas se mantinham em alta ainda, exatamente por decorrência da matriz Social Democrata de suas políticas públicas e normas reguladoras. Neste período Hutton chegou a sustentar que isto ocorria em face de que tais países insistiam em ignorar as injunções positivas do laissez faire econômico, persistindo com suas inflexíveis regras de trabalho e controle de capitais. ${ }^{16}$

Claro que nem parte dos países da Europa Central resistiram ao neoliberalismo em sua totalidade, inclusive alguns deles optaram por estabelecer políticas de 13 Neste ponto, Ohmae refere que este mercando globalizado foi criando progressivamente a ilusão de um mundo sem fronteiras (borderless world), caracterizado por não conter qualquer tipo de barreiras a sua operação em ambientes de negócios totalmente livres que poderiam ajudar a criar igualdade e providenciar grandes e qualificadas chances à maior parte da população. OHMAE, Kenichi. The Borderless World: Power and Strategy in the Global Marketplace. London: Harper Collins Publishers, 1990.

14 SILVA SÀNCHEZ, Jesús-Maria. L'espansione del diritto penale. Aspetti della politica criminale nelle società industriali, p.11.

15 SILVA SÀNCHEZ, Jesús-Maria. L'espansione del diritto penale. Aspetti della politica criminale nelle società industriali, p.11.

16 HUTTON, Will. The World We're in. London: Time Warner Books, 2002, p.237. 
restrições ao Estado do Bem-Estar Social, principalmente em face dos limites orçamentários na gestão pública que geraram reavaliações sobre os sistemas de taxas e benefícios a desempregados mais antigos. De qualquer sorte, tais cenários trouxeram positivas aproximações entre os setores públicos e privados para encontrarem estratégias e formas de melhor gerenciamento de crises institucionais, algumas mais compromissadas com o desenvolvimento livre do mercado, outras com os direitos e garantias sociais.

Por certo que há estreita relação entre Sociedades e Mercados mais estabilizados por políticas públicas e privadas de inclusão social - e os menos estabilizados - e suas taxas de criminalidade e violência.

Em verdade, o advento do neoliberalismo tem sido acompanhado de rápida expansão de uma cultura radical e irracional do consumo e das profundas mudanças em como se relaciona com a sociedade e reciprocamente. Com isto em mente, é importante debater o desenvolvimento desta cultura consumerista como tendência global e seu papel à formação de identidades pessoais, já que com o declínio de estruturas sociais e mesmo de classes/categorias sociais tradicionais até então existentes, causadas pela transição provocada pelo mercado e pela cultura neoliberal associada à promoção do ideal de mobilidade pessoal e social livres (enquanto consumidores) que boa parte da população Ocidental (no mínimo) vem tendo, há crescentes buscas para encontrar outras formas de sentimentos de pertencimento comunitário.

A melhor maneira de evidenciar isto é percebendo como se estrutura e funciona esta cultura neoliberal, centrada fundamentalmente nas diversas e simbólicas formas de nossas posses e propriedades (ou possessões, como quer Hayward), associada a comportamentos de consumo exacerbados que só aumentam a percepção de incluídos e excluídos sob o ponto de vista do acesso a determinados bens, e mesmo em face da fruição do Mercado como elemento formativo da comunidade e das suas relações. ${ }^{17}$

17 HAYWARD, Keith J. City Limits: Crime, Consumer Culture and the Urban Experience. London: The Glasshouse Press, 2004. Ver também neste sentido o interessante trabalho de CAMPBELL, Collin. The Puzzle of Modern Consumerism. In: LEE, M. J. (Org.). The Consumer Society Reader. Oxford: Blackwell Publishers pp. 48-72, 2000. 
De certa forma uma das preocupações da moderna teoria do consumo é porque se deseja tanto ou porque o homem contemporâneo tem esta ilimitada fome por mais coisas. A explicação mais padrão que se tem constituído para tais questões é o que se chama de incrível aumento da procura por produtos em face da explosão de emulações sociais de consumo, associadas com as violentas estratégias de manipulação dos desejos do consumidor pelo mercado. Como diz Veblen, as pessoas desejam porque commodities significam riqueza pessoal e status, o que implica reconhecer ser uma das primeiras motivações por detrás das ações humanas, no mínimo, a fachada da riqueza pessoal. ${ }^{18}$

É de se lembrar de Kal Marx quando fazia referência a este tipo de cultura e comportamento como fetichismo de mercado, o que autorizaria - a partir desta ideia de fetichismo - a ver aquelas commodities como surgidas a partir de processos progressivos de alienação do trabalho em face de seu produto e do seu processo de produção. ${ }^{19} \mathrm{~A}$ incrível dependência da mecanização e autonomização do sistema de produção capitalista significa que o trabalho deixa de ser uma saída à criatividade humana, transformando-se em desumanização. Em face disto, o trabalho transformou-se em pura atividade instrumental e meio para atingir outros fins, fragilizando-se os aspectos identitários do trabalhador no particular.

Os elementos ora expostos atingem certo grau de convergência no debate acadêmico contemporâneo, notadamente sobre as razões pelas quais se consume tanto e tão mal, o que não tem sido tão aclarado de maneira mais tranquila é porque tais elementos da sociedade capitalista atual criam tantos desvios da natureza penal.

Neste ponto, é possível retornar às teorias criminológicas para um início de reflexão, por exemplo, quando se arguiu que a cultura do consumismo exacerbado cria desvios de condutas porque oferece aos criminosos meios de superar as convenções sociais que regulam rotinas banais do dia a dia, operando justamente nos excessos cometidos por esta sociedade do consumo. Em tais 18 VEBLEN, Thorstein. Conspicuous Consumption. In: LEE, M. J. (Org.) The Consumer Society Reader. Oxford: Blackwell Publishers, 2000, pp 31-47.

19 MARX, Karl. The Fetishism of the Commodity and its Secret. In: LEE, M. J. (Org.) The Consumer Society Reader. Oxford: Blackwell Publishers, 2000, pp. 10-18. Ver também o texto MARX, Karl. O Capital. Vol.III. São Paulo: Centauro Editora, 2005. 
contextos, tem havido tentativas para atualizar a teoria da anomia, que expressa a ideia de que onde há vácuos entre as expectativas dos indivíduos em termos de riqueza pessoal, segurança e chances reais de crescimento, situações de comportamentos desviantes e não conformados podem surgir. ${ }^{20}$

Não é difícil ver que estes vácuos estão presentes no cotidiano dos mercados e das relações sociais, basta atentar para o interesse generalizado (e patológico) que a cultura contemporânea tem pela fama, a explosão dos realities televisivos, as novas tendências musicais que partem do hip hop até o rapper (veja-se o álbum Get Rich or Die Tryin, terceiro do rapper 50 Cent, lançado em parceria com a gravadora Interscope, em 2003), dentre outros. O problema é que, como diz Furlong,

It is possible that popular culture gives many young people the idea that they can be rich and famous too, the question that strain theory may be useful in answering is what happens when they realise that they are not going to achieve this by legitimate means. ${ }^{21}$

Em outras palavras, sob a perspectiva se que está tratando o tema, em vez desta cultura globalizada trazer identidades sociais concretas e orgânicas relacionadas à convivência social cotidiana e histórica, ela cria espaços que geram identidades efêmeras baseadas em envolvimento como consumidores de grandes mercados - e não civilizações -, o que potencialmente troca segurança comunitária com ideais imaginários e artificiais, porque resultado de manipulações de demandas pessoais e interpessoais.

Estes ideais imaginários vão aos poucos se incutindo no superego dos indivíduos, e gradualmente começam a ocupar o lugar de formas compartidas de vida em conjunto - tanto de inclusão como de exclusão social -, reforçados pelas mídias de massa que geralmente não se preocupam com análises mais

20 Ver o texto de BURKE, Roger Hopkins. An Introduction to Criminological Theory. Cullumpton: Willan Publishing Campbell, 2001.

21 FURLONG, Andy \& CARMEL, Fred. Young People and Social Change: Individualization and Risk in Late Modernity. Buckingham: Open University Press, 2002, p.38. Ver também o texto de Dean, pois adverte para o fato de que the neo-liberal economy doesn't provide symbolic identities, that is, sites from which we see ourselves. Rather it provides opportunities for new ways for me to imagine myself. DEAN, Jodi. Enjoying Neoliberalism. Available at: http://www.longsunday.net/long_sunday/files/enjoying_neo-liberalism.doc, 2005, acesso em 29/02/2016, p.03. 
aprofundadas das causas destes fenômenos. ${ }^{22} \mathrm{O}$ resultado disto é a formatação de um indivíduo cuja consciência os chama para aproveitar a vida à custa de muitos que não têm acesso a isto, o que fomenta cenários de alta tensão comunitária (entre os que podem e os que não podem ter este acesso, no mínimo).

Consequências traumáticas sob o ponto de vista social decorrem daqui, semelhantes ao que Elias ${ }^{23}$ chama de ruptura do processo civilizatório, com o aumento da instrumentalidade econômica das relações sociais e institucionais, somado ainda à metafórica (e por vezes real) ideia do Estado de Guerra e Violência Hobbeseniano de todos contra todos, o que implica, seguramente, altos índices de marginalização dos segmentos menos apoderados da Sociedade, com a polarização das iniquidades. Este é um campo fértil à atração de comportamentos conjunturais contrários a isto, inclusive alguns de natureza criminal. Com diz o antropólogo Marc Augé:

Una prima osservazione riguarda i caratteri stessi della società moderna, la tesi secondo la quale l'avvento della modernità avrebbe portato alla nascita di un ordine sociale più felice e sicuro è oggi scossa dall'evidenza pragmatica di un mondo denso di pericoli. Una seconda osservazione riguarda la pernuria sociale di "sicurezza ontológica", dalla quale provengono tutte le altre particolari tipologie di preoccupazione, timore e paura. I processi di trasformazione connessi alla modernità, generano in tutti noi uno stato di continua e profonda insicurezza ontologica. Il senso di paura nutre nell'inconscio la percezione delle incertezze che fronteggiano l'umanità nel suo complesso. ${ }^{24}$

22 Neste ponto é interessante a experiência do Osservatorio di Pavia, que se constitui no ano de 1994 como instituto de pesquisa e análise de comunicação, com objetivo fundante de tutelar o pluralismo social, cultural e político nos meios de comunicação, ocupando-se principalmente da compilação e divulgação da relação entre Mídias e Segurança. Ver o sítio do Observatório: http://www.osservatorio.it/, acesso em 09/03/2016. Em pesquisa feita em 2009, o Observatório registra que: Il dato della "percezione dell'insicurezza" invece di seguire la "criminalità effettiva", è molto influenzato dalla mediatizzazione della criminalità, producendo così quello scollamento tra "criminalità percepita" e "criminalità effettiva". Apesar de não termos este tipo de pesquisa no Brasil tão detalhada, pode-se seguramente dizer que aqui passa o mesmo. Ainda vale a advertência de GARAPON, Antoine. I custodi del diritto, Giustizia e democrazia. Milano: Feltrinelli, 1997, p.86, ao dizer que: L'opinione pubblica è oggi più incline a identificarsi nella vittima più che nell'arbitro, nel governato più che nel governante, nel contropotere più che nel potere, nel giustiziere più che nel legislatore.

23 ELIAS, Norbert. The Civilising Process. Oxford: Blackwell Publishing, 2003. Ver também outro texto do autor chamado The Theory of the Civilizing Process and Its Discontents. In http://www.norberteliasfoundation.nl/docs/pdf/GoudsblomDiscontents.pdf, acesso em 29/02/2016.

24 AUGÉ Marc. Le nuove paure. Cosa temiamo oggi. Torino: Bollati Boringhieri, 2013, 
É preciso reconhecer, por outro lado, que a ideia de que certos tipos de relações de mercado e cultura capitalista podem influenciar pessoas no que diz respeito a comportamentos desviantes não é nova, eis que há várias teorias sobre isto desde o século XIX e inícios do século XX (períodos de fortalecimento do liberalismo clássico), já noticiando muitos problemas os quais se está reconhecendo hoje de forma mais clara e intensa. ${ }^{25}$

NadicçãodeLea, háalgunsparâmetrosdeaclimataçãoindividual muitosemelhantes nas sociedades ocidentais em face do avanço capitalista: (i) a brutalização do indivíduo como ser solidário com o outro (transformando-se em criatura); (ii) o engajamento do indivíduo e a aceitação do sistema, notadamente o que pode usufruir dele; (iii) o enfrentamento por parte do indivíduo do sistema, pela via de sua mudança por outro sistema (socialismo, comunismo), a partir de procedimentos políticos válidos sob o ponto de vista da legitimidade e da legalidade; (iv) o enfrentamento por meio da criminalidade (podendo se constituir tais comportamentos via oblíqua/ilícita de formatação de novos beneficiados e incluídos no sistema). ${ }^{26}$

Mesmo que se considere tal análise como muito simplista em alguns aspectos, notadamente no que diz à sua abordagem que no sistema capitalista os pobres tendem a roubar a propriedade dos ricos, a verdade é que a criminalidade hoje está totalmente dispersa, tanto entre classes sociais distintas como entre as mesmas classes sociais, todavia apresenta alguns indicadores de comportamentos que se têm percebido em termos históricos nas experiências dos países ocidentais tanto pobres como ricos.

E mais, muitas vezes as ações de brutalização do sistema capitalista, que se projetam em condutas de indivíduos incluídos nele, provocam reações igualmente brutalizantes: ações de sofisticada criminalidade complexa (lavagem de dinheiro,

p.39. Adverte o autor ainda que: L'organizzazione e la gestione della "sicurezza ontologica" è uno dei problemi maggiori di questa società moderna di fine secolo, perché costringe ognuno a tenere sotto controlo le sue ansie. Na mesma direção, com avaliações mais agudas, GIDDENS, Anthony. The Consequences of Modernity. Cambridge: Polity Press, 1990.

25 Ver o trabalho da Escola Criminológica de Chicago na obra de GARLAND, David. The Culture of Control: Crime and Social Order in Contemporary Society. Oxford: Oxford University Press, 2001.

26 LEA, John. Poverty, Crime and Politics: Frederich Engels and the Crime Question. In: LEA, John and PILLING, Geoffrey (Org.). The Condition of Britain: Essays on Frederich Engels. London: Pluto Books, 1996. 
corrupção, evasão de divisas, tráfico ilícito de influências, tráfico de drogas, etc.), que provocam, direta ou indiretamente, reações de baixa criminalidade (roubo, furto, estelionato, crimes de falso, homicídios, tráfico de drogas, etc.). ${ }^{27}$

Já aqueles que aceitam o sistema por estarem incluídos nele, veem-se vivendo suas vidas como se estivessem isolados e independentes de seus semelhantes, gerando processos de dissolução da humanidade, transformando-a em mônadas. Lembra Lea que Engels defendida a tese de que esta dissolução criaria indivíduos que não se importariam com nada além de seus interesses pessoais e econômicos. ${ }^{28}$ Como consequência, muitas destas pessoas não seriam capazes de resolver suas diferenças de forma amigável e racional, optando pelo uso da violência com as próprias mãos, ou ainda pelas batalhas judiciais, o que constituiria mais um estímulo material à revolução; enquanto a consciência de classe do proletariado cresce ela deixa atrás de si muitas formas de crime, enquanto alimenta seu ódio pela hegemonia burguesa.

A tradição histórica e ainda presente na resposta estatal para cenários como estes é (quando ocorre), não raro, predominantemente legislativa, criando mecanismos mais repressivos do que preventivos de combate à criminalidade e à proteção dos bens referidos; os quais, sem as devidas políticas públicas de gestão antecipatória e responsabilidade jurídica efetiva, criam outras tipologias de colapso do sistema de garantias (individuais e sociais), dentre os quais, os riscos de invasão excessiva nas liberdades civis, na privacidade e na intimidade de pessoas físicas e jurídicas.

Sociedades em contínua aceleração como a nossa demandam novos paradigmas regulatórios e de gestão, centrados em perspectivas de colaboração emancipadora entre Estado, Sociedade e Mercado, com níveis de transparência,

27 Como diz Lea, Brutalisation, it appears, occurs simply because of the demoralising effects of the treatment of the working class by the bourgeoisie, being treated as something subhuman may lead inexorably to criminality, at least according to Engels. LEA, John. Poverty, Crime and Politics: Frederich Engels and the Crime Question. In: LEA, John; PILLING, Geoffrey (Org.). The Condition of Britain: Essays on Frederich Engels, p.19.

28 Vale aqui também a advertência de AUGÉ Marc. Le nuove paure. Cosa temiamo oggi, p.44: La vita moderna impone, come si sa, di vivere con gli stranieri, ma vivere con gli stranieri è in ogni epoca una vita precaria, snervante e impegnativa. Lembra o autor aqui a reflexão de BAUMAN, Zygmunt. Postmodern Ethics. Oxford: Blacwell Publishers, 1993, no sentido de que a incerteza endêmica conectada à presença do outro/estrangeiro encontra vazão no esforço contínuo de controlar a construção do espaço social, punindo todas as ações e comportamentos que se desviam disto. 
participação e deliberação mais compartilhadas entre todos os protagonistas, isto sob a ótica de metodologias de abordagem e procedimentos das ações de concertação entre interesses públicos e privados. ${ }^{29}$

Paralelo a isto, há o caos instalado nesta Sociedade de Riscos envolvendo não somente a macrocriminalidade nacional e internacional (tráfico de entorpecentes, de pessoas, de órgãos humanos, lavagem de dinheiro); mas também a microcriminalidade organizada (crime de licitações envolvendo pequenos municípios ajustados com pequenas e médias empresas, crimes contra a ordem econômica de baixa monta, crimes contra o consumidor, dentre outros). E este caos precisa de tratamento imediato, não exclusivamente de natureza penal, mas também pelo Direito Penal.

Em termos de continente latino-americano, os dados e as estatísticas decorrentes destas questões até agora enfrentadas evidenciam suas procedências no âmbito da violência que se tem produzido, isto é, enquanto se tem $9 \%$ da população do mundo, o percentual de homicídio é de $27 \%$, tendo 10 dos 20 países com maiores taxas de homicídio no planeta. ${ }^{30}$

29 Ver os textos de FARIA, José Eduardo. Direito e Globalização Econômica: implicações e perspectivas. São Paulo: Malheiros, 1996; e BAUMANN, Zygmunt. Modernidad Líquida. México: Fondo de Cultura Económica, 2008.

30 UNODC (2011). World Report on Homicides. In: https://www.unodc.org/gsh/, acesso em 07/03/2016. Ver também o excelente texto: América Latina Frente al Espejo: dimensiones objetivas y subjetivas de la inequidad social y el bienestar de la región. Santiago, CEPAL 2010. In: http://www.cepal.org/es/publicaciones/2965-america-latina-frenteal-espejo-dimensiones-objetivas-subjetivas-la-inequidad, acesso em 07/03/2016. 
Veja-se a tabela da pesquisa social que se fez neste relatório da UNDOC ${ }^{31}$ :

\begin{tabular}{|c|c|c|c|c|c|c|c|}
\hline \multirow{2}{*}{\multicolumn{8}{|c|}{ Arquivo Editar Visualizar Janela Ajuda }} \\
\hline \multirow{2}{*}{\multicolumn{6}{|c|}{$\begin{array}{l}\text { Arquivo } \\
\text { Inditar }\end{array}$}} & & \\
\hline & & SeguridadCiudada... $\times$ & & & & (?) ख & Rogério - \\
\hline \multicolumn{8}{|c|}{$\begin{array}{l}\text { Tabla No 1: La delincuencia y su importancia. } \\
\text { P. En su opinión ¿Cuál considera Ud. que es el problema más importante. }\end{array}$} \\
\hline & País & \multicolumn{2}{|c|}{ Problema más importante en el país } & Delincuencia & $\begin{array}{l}\text { Pandillas/ } \\
\text { violencia }\end{array}$ & $\begin{array}{c}\text { Delincuencia/ } \\
\text { Violencia/Pandillas }\end{array}$ & \\
\hline & \multicolumn{3}{|c|}{ Desocupación/desempleo } & & & & \\
\hline & Paraguay & Desocupación/desempleo & 30 & 28 & 1 & 29 & \\
\hline & Colombia & Desocupación/desempleo & 23 & 15 & 13 & 28 & \\
\hline & \multicolumn{3}{|c|}{ Delincuencia/seguridad pública } & & & & \\
\hline & Venezuela & $\begin{array}{c}\text { Delincuencia/seguridad } \\
\text { pública }\end{array}$ & 61 & & 1 & 62 & \\
\hline & Costa Rica & $\begin{array}{c}\text { Delincuencia/seguridad } \\
\text { pública }\end{array}$ & 45 & & 5 & 50 & \\
\hline & El Salvador & $\begin{array}{l}\text { Delincuencia/seguridad } \\
\text { pública }\end{array}$ & 40 & & 11 & 51 & \\
\hline & México & $\begin{array}{c}\text { Delincuencia/seguridad } \\
\text { pública }\end{array}$ & 39 & & 2 & 41 & \\
\hline & Uruguay & $\begin{array}{c}\text { Delincuencia/seguridad } \\
\text { pública }\end{array}$ & 40 & & 1 & 41 & \\
\hline & Argentina & $\begin{array}{c}\text { Delincuencia/seguridad } \\
\text { pública }\end{array}$ & 34 & & 1 & 35 & \\
\hline & Panamá & $\begin{array}{c}\text { Delincuencia/seguridad } \\
\text { pública }\end{array}$ & 33 & & 1 & 34 & \\
\hline & Ecuador & $\begin{array}{l}\text { Delincuencia/seguridad } \\
\text { pública }\end{array}$ & 33 & & 1 & 34 & \\
\hline \multicolumn{2}{|c|}{10} & OY Gت & S & w恝 数 2 & & 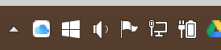 & $\begin{array}{c}14: 14 \\
77 / 03 / 2016\end{array}$ \\
\hline
\end{tabular}

É de se ter presente que a violência ativa que se manifesta nestes indicadores na América Latina (por exemplo, e para não dizer que é só no Brasil), representa somente parte das manifestações das relações econômicas, sociais e de poder estabelecidas no marco da (in)evolução do capitalismo neoliberal.

Veja-se que, por outra via, as respostas - mais legislativas, retóricas e curativas do que preventivas - oriundas do Estado como garantia da ordem e da segurança públicas têm proliferado de forma muito mais rápida do que os sistemas de informação e conhecimento das causas do problema da insegurança, violência e vitimização social. ${ }^{32} \mathrm{E}$ é importante ter consciência sobre o porquê isto ocorre, 31 UNODC (2011) World Report on Homicides. In: https://www.unodc.org/gsh/, acesso em 07/03/2016, p.05

32 Para fins de registro, La literatura ha dado muestras evidentes de que no hay una correspondencia entre delito y temor. Investigaciones en Estados Unidos de los años sesenta ya demostraba que el aumento del temor no estaba correlacionado con un aumento de la criminalidad. El temor es un fenómeno autónomo que no necesariamente se va a mover en la misma dirección que la victimización. LAGOS, Marta e DAMMERT, Lucía. La Seguridad Ciudadana El problema principal de América Latina. In: http://www.latinobarometro. org/documentos/LATBD_La_seguridad_ciudadana.pdf, acesso em 08/03/2016, p.33. Ainda relatam as autoras que: Un elemento que sí comparten los países es que el temor a la delincuencia ha cambiado el comportamiento de las personas y sus estilos de vida, afectando el funcionamiento de las sociedades. Por ejemplo, las personas evitan salir de noche y se encierran más en sus hogares, se comienzan a implementar más medidas de seguridad -que según el nivel de ingresos puede ir desde perros hasta armas, pasando por rejas y cercos eléctricos. Otros, en tanto, pueden incluso cambiarse de una casa a un departamento porque les otorga mayor sensación de seguridad y el surgimiento de urbanizaciones cerradas también está asociado -entre otros factores- a la inseguridad. 
ou seja, a exigência de conhecimento/informação rigorosos da problemática em comento se vê premida por demandas de ações resolutivas advindas da opinião pública amedrontada, gerando extremada politização (eleitoral, partidária, ideológica) do enfrentamento disto, afastando-se das necessárias análises técnicas e fundamentadas.

Tudo isto é próprio da Sociedade de Riscos em que se vive, como já advertiu Beck $^{33}$ Nesta Sociedade, os riscos sociais, políticos e econômicos tendem a escapar do controle institucional ordinário do Estado. As próprias instituições privadas e de mercado começam a criar riscos que não podem tampouco controlar, constituindo-se que o Beck chama de irresponsabilidade organizada, formatada por mecanismos institucionais e culturais a partir dos quais elites econômicas e políticas mascaram as origens e as consequências dos riscos e dos perigos catastróficos que rodeiam a todos. Na dicção de Demichelis:

Siamo passati dalla Società classista alla Società del rischio, cioè da una società costruita sul concetto di «produzione e distribuzione della ricchezza» ad una realtà in cui ci si preoccupa della «distribuzione dei rischi». Nello specifico per rischio si intende l'aleatoria conseguenza di decenni di sviluppo scientifico e tecnologico senza pari nella Storia dell'Uomo, che hanno ampliato il grado di incertezza nel futuro e la consapevolezza (o la percezione) di Istituzioni incapaci di arginare la violenza e dare sicurezza al citadino. ${ }^{34}$

Agora, naqueles casos em que o sentimento de insegurança é tal que aumentam as demandas em face do Estado e dos serviços privados por maior segurança, e quando a violência e a delinquência reais aumentam, chegando a níveis maiores de organização que desafiam permanentemente as instituições públicas, pergunta-se: qual a função do Direito?

33 BECK, Urlich. La sociedade del riesgo. Hacia una nueva modernidade. Barcelona: Paidós, 1998. Novamente Augé lembra que: la difficoltà di porre una distanza cognitiva tra il sé e l'altro, provoca la destabilizzazione del sistema di orientamento e l'abbassamento della soglia di tolleranza alla frustrazione, dovuta alla mancanza di controllo sulle circostanze della vita.

34 DEMICHELIS, Lelio. Società o Comunità. Roma: Carrocci Editore, 2011, p.49. 


\section{É POSSÍVEL CONTER OS RISCOS DESTES FENÔMENOS PELA VIA DO DIREITO? ALGUMAS ABORDAGENS FILOSÓFICAS}

Todos sabem que o direito, ao menos fundamentalmente, se expressa por meio de proposições que se denominam jurídicas, ou seja, em códigos, leis, constituições, etc. Estas normas, ou ordenamento jurídico, regem a vida do indivíduo como cidadão (sujeito a deveres e direitos), reconhecido pela comunidade a que pertence e protegido pelas instituições de que faz parte, como também pelo Estado. Nesta relação de respeito recíproco, ou não, a sociedade encaminha seu processo de desenvolvimento, enfrentando as delimitações inscritas pelas convenções forjadas em leis.

Estudar o direito significa, a partir desta visão globalizante, conhecer as relações sociais de determinada conjuntura; observar como se dá a criação da lei; quais seus pressupostos e referências; que tipo de fatores influenciam o seu surgimento ou mesmo alcance; como se dá, enfim, a constituição dos códigos de condutas e comportamentos sociais.

Desta forma, fácil se torna a percepção de que o Direito ou o conhecimento jurídico não pode ser definido com rigor absoluto e definitivo. Como diz Ferraz $\mathrm{Jr}^{35}$, este conhecimento é constituído de um grande número de símbolos e ideais reciprocamente incompatíveis. De outra parte, porém, não deixa de ser um dos mais importantes fatores de estabilidade social, eis que pretende garantir um espaço de ordem e segurança para a efetivação e coexistência das mais diversas aspirações/interesses sociais.

É assim que a busca de uma compreensão universal para o Direito se apresenta como, fundamentalmente, questão cultural, pois a possibilidade de se descobrir a essência ${ }^{36}$ do saber jurídico tem a finalidade de conferir aquela segurança referida

35 FERRAZ JR., Tercio. Introdução ao Estudo do Direito. São Paulo: Atlas, 1990, p.33. Um dos exemplos citados pelo autor é quando um homem comum se vê envolvido num processo judicial, por mais que ele esteja seguro dos seus direitos, a presença do outro, contestando-o, cria-Ihe uma certa angústia que desorganiza sua tranquilidade.

36 Esta questão da essência remete para uma questão cultural muito específica do Ocidente que tem a ver com a concepção de língua no seu relacionamento com a realidade que ela descreve ou mesmo cria. Uma possível teoria essencialista do direito crê que a língua é 
aos estudos e compreensão dos fenômenos sociais, pois "Uma complexidade não reduzida a aspectos uniformes e nucleares gera angústia, parece subtrair-nos o domínio sobre o objeto. Quem não sabe por onde começar, sente-se impotente e, ou não começa ou começa sem convicção." ${ }^{37}$

Diante da amplitude deste estudo, imprescindível, para conhecer-se o direito, conhecer-se o espaço político, cultural, ideológico, econômico e filosófico em que está inserido e, para tanto, somente com as categorias ou conceitos jurídicos não se consegue avaliar com detalhamento tal situação, necessitando, hoje mais do que nunca, lançar-se mão de outros ramos do conhecimento para socorrer as denominadas ciências jurídicas, como a psicologia, a antropologia, a economia, as ciências políticas, e a filosofia, aqui, utilizando seus arcabouços teóricos para investigar o fenômeno jurídico.

As concepções de mundo e de homem de que se têm notícias sofreram mutações no decorrer dos tempos. Dos povos gregos até a modernidade, o desenvolvimento do conhecimento humano e o advento de novos modelos de ciência permitiram a análise histórica da evolução das investigações filosóficas e políticas.

Nos tempos remotos dos séculos XII a IX AC, por exemplo, a cultura grega encontrou no mito a forma privilegiada de se estruturar e de se organizar. $A$ força propulsora da faculdade mitogênica, isto é, aquilo que desafia o homem a produzir mitos, é o mistério, que envolve a vida, o ser e suas relações com a natureza. $O$ homem sente-se como jogado na existência em meio à multiplicidade de fenômenos, que o desafiam e que ele tem de ordenar ou organizar, significativamente, em função de um viver razoável.

Já a partir do império romano e sua proposta de expansão e conquista, houve sério recuo nas investidas de debates filosóficos ou preocupações de desvendar a posição do homem comum diante do mundo. De certa forma, a visão teológica que justificava o poder do imperador, hegemonicamente, garantia os privilégios da corte e a mantença de linhagem da política oficial, indo tal quadro se desenvolver até praticamente o século XI e XII, com poucos registros históricos desviantes.

um instrumento que designa a realidade, donde a possibilidade dos conceitos linguísticos refletirem uma presumida essência dos objetos estudados.

37 FERRAZ JR., Tércio Sampaio. Introdução ao Estudo do Direito, p.37. 
Neste particular, a avaliação de desenvolvimento teórico das ações de natureza político-prática dos romanos é reveladora de total falta de preocupação com problemas científicos ${ }^{38}$ ou especulativos próprios à espécie.

Theodor Viehweg ensina que a jurisprudência romana é bastante esclarecedora sobre a forma procedimental de tratar o direito como saber jurídico voltado à resolução de conflitos, ou seja, um saber prático, possuindo certo rigor (estabilidade) na construção de um discurso jurídico uniforme e suficientemente abstrato para ser geral. Desta prática jurisdicional, decorre o surgimento de conceitos e definições mais duradouras, vinculando as ações públicas e privadas na prática de seus ofícios. ${ }^{39}$

$\mathrm{Na}$ concepção de Ferraz Jr., esta jurisprudência romana poderia ser caracterizada como saber prudencial, dotado de uma racionalidade dialética própria, oportunizando o confronto de opiniões em torno das premissas que fundamentam o raciocínio justificador de seus atos e decisões. Essa postura outorga ao jurista o dever de construir o Direito, é óbvio, respeitando os padrões de comportamento previamente aceitos e determinados ${ }^{40}$, mas demonstrando que estava garantida a possibilidade de se constituir cenários de argumentações e provas das pessoas envolvidas.

Para atender a tantas demandas e em tão vasto território, o conhecimento jurídico prático romano teve de contar com o referido grau de abstração e generalidade, capaz de recepcionar divergentes pretensões jurídicas. Assim, este saber funcional assumiu a forma de um programa decisório em que eram formuladas as condições para a decisão correta/permitida.

38 É bem verdade que a ideia de ciência do direito só vai se formar na Idade Moderna, passando pela contribuição da Escola Histórica alemã.

39 VIEHWEG, Theodor. Topica y jurisprudencia. Madrid: Taurus, 1984. As responsa dos jurisconsultos romanos eram típicos modelos deste comportamento, adotando técnicas da dialética grega, quando confrontavam posições e ideias sobre os temas discutidos, tentando abstrair de elementos normativos já dispostos.

40 FERRAZ JR., Tércio Sampaio. A Ciência do Direito. São Paulo: Atlas, 1986, p.20. Informa o autor que o conceito de prudência aqui é o trabalhado por Aristóteles, isto é, conhecimento moral capaz de sopesar, diante da mutabilidade das coisas, o valor e a utilidade delas, bem como a correção e a justeza do comportamento humano. A filosofia grega denominava este agir prudencial de fronesis, que designava a capacidade de julgar sopesando soluções, situações e tomando as decisões. 
Com tal programa decisório, chega-se à autonomia e à independência do próprio Direito como saber, para se estabelecer como instituição reguladora dotada de neutralidade e validade para todos, em nome da qual se restaura a ordem social instituída e desrespeitada. Este saber prático dos romanos vai implementando posições e comportamentos diante do mundo que não é somente contemplativo e descritivo, mas fundamentalmente ativo e prescritivo. A partir daqui, vão-se desdobrar teorias jurídicas que buscarão a cientificidade deste saber. ${ }^{41}$

Do século XV até o XVII a ciência jurídica vai contar com o que se denominou de Era do Direito Racional, caracterizando-se pela influência dos sistemas racionais na teoria jurídica. Auctoritas e Ratio haviam dominado o pensamento jurídico medieval cujo caráter dogmático assinala um respeito pelos textos a serem interpretados como pontos de partida das séries argumentativas. Com esta situação, o humanismo renascentista modifica a legitimação do Direito Romano, purificando e refinando o método da interpretação dos textos e, com isto, abrem-se as portas para a entrada da ciência moderna na teoria jurídica. ${ }^{42}$

E o que isto significa? Significa a promessa da ciência moderna (do Direito) de que o conhecimento racional produzido com base em premissas absolutas, seguras e certas podem levar ao conhecimento das essências perenes da vida humana e de suas relações, auxiliando no processo do dominá-las para os fins que se desejam, servindo melhor à espécie humana. ${ }^{43}$

41 Não demorou muito para que o direito positivo passasse a se caracterizar por contar com tratamento técnico e formal de assuntos do interesse dos indivíduos e da sociedade, baseado em análise dos textos e das situações concretas com fundamento no estilo argumentativo da retórica prudencial, buscando de certa forma afastar os interesses e as emoções do exegeta e dos valores envolvidos. Para além disto, a questão do fundamento do direito passa a ser mediada pela soberania, pela justificação do poder e de seu exercício, aqui, por óbvio, respeitando um princípio centralizador: assim como todos os seres tinham a sua unidade de convergência em Deus, assim como a verdade só podia ser uma, assim também o direito só podia ser um, dentro de um determinado território, de uma determinada esfera de poder. Ver o texto de

42 Ver o texto de STEGMÜLLER, Wolfang. A Filosofia Contemporânea. São Paulo: Edusp, 1977.

43 Sobre o tema anota Beck: the security dream of first modernity was based on the scientific utopia of making the unsafe consequences and dangers of decisions ever more controllable. BECK, Urlich. Living in the world risk society. In: Economy and Societ, . Vol. 35. Number 3. August 2006: 329/345. http://www.tandfonline.com/toc/reso20/current, p.334. 
Decorre também daqui a formatação de premissas como a de que somente no âmbito do Estado Nação (com povo, sistema normativo e território delimitados) as conquistas da Modernidade poderiam se efetivar, tais como a própria Democracia e o Estado do Bem-Estar. ${ }^{44}$

Entretanto, como adverte Rorthy, esta matriz de ciência moderna aborda os problemas que levantam como se fossem questões perenes, eternas no âmbito de suas premissas e mesmo conclusões ${ }^{45}$, isto porque, em verdade, o conhecimento afigura-se como uma representação do que está fora da mente, decorrendo daí que, para se entenderem as possibilidades e a natureza do conhecimento, é necessário se entender a forma pela qual a mente se habilita para construir tais representações. Ao não se compreender este processo fenomenológico de construção do conhecimento, estar-se-á ratificando aquela ideia de que:

(...) philosophy became, for the intellectuals, a substitute for religion. At the beginning of our century, this claim was reaffirmed by philosophers (notably Russel and Husserl) who were concerned to keep philosophy rigorous and scientific. ${ }^{46}$

A Teoria do Conhecimento da Idade Moderna nasce com esta pretensão de buscar/encontrar aquilo que compele a crer no que se desvelou por meio das percepções visuais das representações extraídas do mundo da vida (dentro dos marcos permitidos pelo espelho da natureza), decorrendo que a filosofia como epistemologia terá como objeto a busca de imutáveis estruturas dentro das quais conhecimento, vida e cultura devem estar contidas - estruturas estas estabelecidas por aquelas privilegiadas representações dadas - e sem sombra de dúvidas que também aos sistemas e aos ordenamentos jurídicos cumprirá tal tarefa. ${ }^{47}$

44 Ver o excelente texto de BECK, Urlich. The cosmopolitan perspective: sociology of the second age of modernity. In: British Journal of Sociology, Vol. 51, Issue No. 1 (January/ March 2000) pp. 79-105, p.82. ISSN 0007 1315, London School of Economics 2000.

45 Diz textualmente o autor que: philosophers usually think of their disciplines as one which discusses perennial, eternal problems - problems which arise as soon as one reflects. RORTY, Richard. Philosophy and the mirror of nature. Princeton: Princeton University Press, 1979, p.03.

46 RORTY, Richard. Philosophy and the mirror of nature, p. 82.

47 The theory of knowledge will be the search for that which compels the mind to belief as soon as it is unveiled. Philosophy-as-epistemology will be the search for the immutable structures within which knowledge, life, and culture must be contained - structures set by the privileged representations that it studies. RORTY, Richard. Philosophy and the mirror of nature, p.160. Isto não durou muito tempo, eis que nos umbrais do século XX, como 
Já aqui caberia a pergunta de Beck, no sentido de se saber o porquê as ciências (inclusive as sociais) se preocupam tanto com o que ainda não sabem?

Because in the face of the production of insuperable manufactured uncertainties society more than ever relies and insists on security and control; and because the argument about the knowing and not-knowing of global risks cancels the established national and international rule systems. ${ }^{48}$

No final do século XIX e início do século XX, pôde-se perceber certa virada reflexiva por parte de alguns filósofos ocidentais, dentre os quais Rorty destaca Dewey, Nietzsche, Bergson e Dilthey, no sentido de que eles incidiram crítica profunda à ideia de verdade como correspondência e conhecimento como representação, problematizando a noção kantiana de filosofia como metacrítica de outras ciências. Com tais comportamentos, estes filósofos sugeriram a possibilidade de exploração do mundo e do conhecimento a partir de outros lugares e bases constitutivas, que não a epistemologia; que não a busca de certezas, estruturas e rigor cognitivos imutáveis. ${ }^{49}$

Os cenários caóticos e complexos anteriormente referidos como causados pelo modelo capitalista atual se apresentam como as novas ameaças artificiais (e não da natureza desconhecida das coisas) ao desenvolvimento sustentável e pacífico das relações humanas, obrigando-se a reconhecer que efetivamente a natureza humana não se encontra em situação de total harmonia e pacificação (matéria que já fora tratada pelos teóricos do contratualismo político e estatal - Hobbes, Locke,

no mito do eterno retorno platônico, just as mathematics had inspired Plato to invent philosophical thinking, so serious-minded philosophers turned to mathematical logic for rescue from the exuberant satire of their critics. RORTY, Richard. Philosophy and the mirror of nature, p.163.

48 BECK, Urlich. Living in the world risk society, p.335.

49 RORTY, Richard. Philosophy and the mirror of nature p.163. É tão forte esta perspectiva de se absolutizar as certezas racionais construídas pela mente e por um conhecimento lógico e matemático - adversário direto do que Russell e Husserl chamavam de psicologismo, que estes autores referiam ser a lógica a essência da filosofia. Neste aspecto, Bertrand Russell chegou a sustentar que: the now logic introduced the same kind of advance into philosophy as Galileo introduced into physics, making it possible as last to see what kinds of problems may be capable of solution, and what kinds must be abandoned as beyond human powers. Moreover, where a solution appears possible, the new logic provides a method that enables us to obtain results that do not merely embody personal idiosyncrasies, but must command the assent of all who are competent to form an opinion. In: RUSSELL, Bertrand. Our Knowledge of the External World. London: Oxford University Press, 1980, p.41. 
Rousseau, etc.) e que, em razão disso, necessita de proteção contra a agressão dos outros, o que entreabre a exigência de organização racional da ordem social. Daqui surge a ideia de pensamento jurídico neutro, conduzindo à formalização e à racionalização, dentre outros sistemas sociais e institucionais do Direito.

Em razão disso, a teoria jurídica (notadamente europeia e, por consequência, a brasileira em sua história), que até então era caracterizada por se fundar em uma teoria da exegese e da interpretação de textos singulares, passa a receber caráter lógico-demonstrativo de um sistema fechado, cuja estrutura dominou e mesmo domina os códigos e os comportamentos jurídicos contemporâneos. A redução das proposições jurídicas a relações lógicas é pressuposto óbvio na formulação de leis naturais, universalmente válidas, a que se agrega o postulado antropológico que vê no homem não um cidadão abstrato, mas como um ser natural, concebido segundo leis naturais.

Assim, a Teoria do Direito na modernidade, se de um lado quebra o elo entre a jurisprudência e o procedimento dogmático fundado na autoridade dos textos romanos, de outro não rompe com o caráter dogmático que, ao contrário, tenta aperfeiçoar ao dar-lhe qualidade de sistema que se constrói a partir de premissas cuja validade repousa na sua generalidade racional, indicadora dos padrões éticos eleitos. Estava, dessa forma, configurado o caminho para a ciência jurídica no estilo moderno, como procedimento empírico-analítico, em sentido eminentemente pragmático, transformando o conjunto de regras que compõem os ordenamentos jurídicos em regras técnicas que visam controlar as situações vigentes a partir daquelas idealmente desejadas/veiculadas pela norma, prevenindo e sancionando desvios provocados. ${ }^{50}$

Eis a Dogmática Jurídica, partindo do pressuposto de que é possível descrever a ordem legal sem nenhum tipo de referência de caráter sociológico, antropológico, político e econômico, apresentando-se como construção teórico-objetiva e rigorosa; elaboração conceitual do direito vigente sem indagação alguma de sua instância ideológica e política. Suas proposições, deste modo, se integram

50 Neste sentido a obra de MACHADO NETO, A. L. Teoria da Ciência Jurídica. São Paulo: Saraiva, 1983. 
dentro de sistema axiomático, elaborado a partir de conceitos, noções, princípios, aforismos e instituições que pretendem completar e fechar o saber jurídico. ${ }^{51}$

Ocorre que este saber jurídico tradicional, encastelado em seus dogmas e institutos fossilizados pelo tempo e pela falta de dialeticidade/sintonia com a complexidade das relações intersubjetivas e institucionais hodiernas, vem trazendo profundas dificuldades aos interesses sociais, eis que revela inegável falta de adequação dos seus mecanismos de prestação de tutela estatal (notadamente jurisdicional) em face dos novos atores sociais e políticos que se embatem no cenário público da comunidade globalizada, e os que suas sinergias produzem em termos de complexidade e riscos, por vezes catastróficos.

Daí a advertência de Beck, no sentido de que:

The narrative of risk is a narrative of irony. This narrative deals with the involuntary satire, the optimistic futility, with which the highly developed institutions of modern society - science, state, business and military - attempt to anticipate what cannot be anticipated..$^{52}$

A ironia aqui decorre das promessas da racionalidade e da ciência modernas, isto é, que as experiências do passado possam nos garantir antecipações seguras dos riscos do presente e do futuro, fazendo com que se acredite que se possa calculá-los e controlá-los - inclusive pela via de sistemas normativos cogentes -, quando, na verdade, presente e futuro escapam da própria compreensão como totalidade, em face de suas complexidades multifacetárias.

51 Posição defendida por WARAT, Luis Alberto. Sobre la Dogmática Jurídica. In: Revista Seqüência, no 02, ano 1, 20 Semestre de 1980, Florianópolis, 1980, pp.33/55. O problema da legitimidade e da valoração do sistema jurídico, agora, não é mais importante, ou ao menos não se encontra localizado na instância vigente e aceita (lógico-formal) de aplicação da lei, eis que os critérios informativos de tal ação são tão somente os que dizem respeito à verificação de sua validade ou invalidade. Arquiteta-se, no âmbito do positivismo jurídico ou do neopositivismo jurídico, entre os operadores do direito verdadeiro pacto de submissão ao sistema jurídico vigente, com mínimas chances de superação do campo estreito de mobilidade política outorgado por ele. Forja-se aqui o que Warat chama de senso comum teórico dos juristas. WARAT, Luis Alberto. Senso Comum Teórico: as vozes incógnitas das verdades jurídicas. In: Introdução Geral ao Direito. Porto Alegre: Fabris, 1994, pp. 13/18.

52 BECK, Urlich. Living in the world risk society, p.329. Segundo o autor: Socrates has left us to make sense of the puzzling sentence: I know that I know nothing. The fatal irony, into which scientific-technical society plunges us is, as a consequence of its perfection, much more radical: we do not know what it is we don't know - but from this dangers arise, which threaten mankind!... In other words, it is irrelevant whether we live in a world which is in fact or in some sense 'objectively' safer than all other worlds; if destruction and disasters are anticipated, then that produces a compulsion to act. 
Mas como viver em face da ameaça dos riscos globais contemporâneos(?), pergunta Beck. ${ }^{53}$ Como reagir quando velhas certezas e paradigmas são quebrados, ou agora revelados como incertezas ou até mentiras? Estes são componentes que geram sentimentos de insegurança, incerteza, instabilidade e temor em face do presente e do futuro, notadamente quando dizem respeito à vida de pessoas, e diante deles é preciso que se tome o que o autor alemão chama de choque do perigo (shock of danger), oportunizando novos começos à natureza humana e onde há novos começos, ações de prevenção e responsabilidade dos auto evidentes riscos que são possíveis, pois as catástrofes começam a ser percebidas como reais e não fictícias, as quais podem ocorrer conosco e não somente com os outros. ${ }^{54}$

Numa outra perspectiva complementar a esta, os sistemas jurídicos modernos criaram a crença social de que rotinas inquebrantáveis poderiam ser asseguradas às relações sociais e institucionais por seus dispositivos normativos, e estas contribuíram de forma muito substantiva à manutenção da ordem e da estabilidade dos ambientes, negócios, atos e reações comportamentais. Entretanto, quando tais rotinas se veem perturbadas por quaisquer razões, eclodem estados de ânsia capazes de alterar inclusive os aspectos mais fortemente radicados na cultura e na expectativa desta modernidade. ${ }^{55}$

53 BECK, Urlich. Living in the world risk society, p.329. Alerta ainda o autor que: Risk does not mean catastrophe. Risk means the anticipation of catastrophe. Risks exist in a permanent state of virtuality, and become 'topical' only to the extent that they are anticipated. Risks are not 'real', they are 'becoming real ' (Joost van Loon). At the moment at which risks become real - for example, in the shape of a terrorist attack - they cease to be risks and become catastrophes. Risks have already moved elsewhere: to the anticipation of further attacks, inflation, new markets, wars or the reduction of civil liberties. Risks are always events that are threatening. BECK, Urlich. Living in the world risk society, p.04).

54 Interessante ver os textos de ARENDT, Hannah. A condição humana. Rio de Janeiro: Forense Universitária, 1989, e ARENDT, Hannah. The Promise of Politics. New York: Schocken Books, 2005.

55 Neste sentido, ver o texto de GUIDENS, Anthony. Le cosnseguenze della modernità. Bologna: Il Mulino, 1994. Como dizem Francesca Vianello e Dario Padovan: La difficoltà di porre una distanza cognitiva tra il sé e l'altro, provoca la destabilizzazione del sistema di orientamento e l'abbassamento della soglia di tolleranza alla frustrazione, dovuta alla mancanza di controllo sulle circostanze della vita. La carenza di sicurezza interpretata a questo modo è, come si sa ormai da tempo, causa di ansia se non di nevrosi, e la percezione della sicurezza dipende in ultima analisi dall'accettazione o dal rifiuto dell'ambiente fisico e sociale. In VIANELLO, Francesca; PADOVAN, Dario. Criminalità e paura: la costruzione sociale dell'insicurezza. Publicado no site http://www.ristretti.it/areestudio/giuridici/studi/ vianello _padovan.pdf, acesso em 06/04/2016. 
A demanda por segurança como direito de construir um espaço social próprio, indene aos riscos da sociedade atual, revela ânimos de temores difusos que se projetam em perigos tangíveis (a criminalidade complexa, os imigrantes, os drogados), que se imagina poder combater e mantê-los longe da civilização prometida. Ledo engano, isto porque

... la condizione moderna è caratterizzata strutturalmente da un senso di insicurezza individuale e collettivo che non potrà mai essere posto in maniera definitiva sotto controllo, proprio perché è la società stessa che lo alimenta continuamente. ${ }^{56}$

Veja-se o exemplo do terrorismo, diante do qual, em nome da proteção da população amedrontada pela falta de segurança, vários Estados têm limitado liberdades e direitos civis, o que é motivo para comemorações da cidadania assustada, decorrendo daí abolições progressivas de sociedades livres, enquanto que o terrorismo não demonstra qualquer recuo, evidenciando as insuficiências das instituições públicas e de seus sistemas normativos de condutas (administrativos, civis e penais). ${ }^{57}$

Portanto, e ao menos provisoriamente, pode-se dizer que os sistemas jurídicos mais dogmáticos, que insistem em se enclausurar na produção de ordenamentos não receptivos à complexidade social hodierna, têm dificuldades de dar conta de suas promessas modernistas de segurança, estabilidade das relações, previsibilidade de resultados, dentre outras. ${ }^{58}$

56 VIANELLO, Francesca e PADOVAN, Dario. Criminalità e paura: la costruzione sociale dell'insicurezza, p.04.

57 Ver os estudos sobre este tema e outros correlatos no texto AGAMBEN, Giorgio. Democracia, en que Estado? Buenos Aires: Prometeo Libros, 2014. Enquanto se escreve este texto acaba de ocorrer um atentado terrorista em Bruxelas, informado por agências de notícias: A Procuradoria da Bélgica confirmou que foram atentados coordenados as três explosões registradas por volta das 8h15 (4h15 de Brasília) desta terça-feira (22) em Bruxelas, na Bélgica, duas no aeroporto internacional da capital, perto dos balcões de check-in no terminal de embarque, e outra na estação de metrô de Maelbeek, localizada próxima a edifícios da União Europeia. Ao menos uma das explosões foi provocada por um homem-bomba. Ao menos 28 pessoas morreram -15 no metrô e 13 no aeroporto - e 55 pessoas ficaram feridas. In: http:// noticias.uol.com.br/internacional/ultimas-noticias/2016/03/22/aeroporto-de-bruxelas-nabelgica-e-fechado-apos-explosoes.htm, acesso em 22/03/2016. Ver um texto interessante sobre temas conexos que é o de WALKLATE Sandra. Crime and community: fear or trust? In: British Journal of Sociology, vol. 49, n. 4, 998, pp. 550-569.

58 Uma das consequências disto é bem definida por Beck: The inequalities of definition (dos riscos) enable powerful actors to maximize risks for 'others' and minimize risks for 'themselves'. Risk definition, essentially, is a power game. BECK, Urlich. Living in the world 


\section{A TÍTULO DE CONSIDERAÇÕES FINAIS PROVISÓRIAS: COMO ESTES CENÁRIOS SE APLICAM AO DIREITO PENAL?}

O Direito Penal no Ocidente se viu fortemente influenciado pelo evolver da ciência moderna anteriormente referida e que contaminou a ciência jurídica como tal, basta ver a perspectiva positivista e liberal daquele que cria a ilusão consensuada de que as formas sociais, e em decorrência, as categorias e os tipos penais, podem figurar como inflexíveis no âmbito da sociedade em que são instituídos (pois garantidores da segurança, da certeza, da previsibilidade e da estabilidade de comportamentos e condutas desejadas espacial e temporalmente), operando, inclusive, como fator de restrição a eventuais mudanças dos padrões de criminalidade normatizada, haja vista os bens jurídicos penais, a tipicidade, a antijuridicidade e a culpabilidade estabelecidos a priori como absolutos. ${ }^{59}$

Se os sistemas jurídicos atuais, operados a partir das promessas da Modernidade referidas, não dão mais conta das complexidades sociais em que atuam, isto sem sombra de dúvidas se aplica - e não poderia deixar de ser diferente -, exemplificativamente, ao Direito Penal.

Importa ressaltar que o respeito ao princípio histórico de ser o Direito Penal a ultima ratio e, em face disto, sua conexa redução de intervenção nos conflitos sociais, tem resultado o efeito reflexo de aplicação, no plano legislativo e jurisprudencial, de outros princípios fundamentais para além da legalidade, a saber, o da ofensividade e da culpabilidade, concretizando o que Pagliaro chama de princípio de ultima ratio em ação. ${ }^{60}$

Há parâmetros igualmente normativos e jurisprudenciais que densificam materialmente a função do Direito Penal como ultima ratio, dentre outros que se pode apontar o merecimento e a necessidade (constitucional e infraconstitucional) de penalizar determinados agentes que cometem ilícitos desta natureza, isto

\footnotetext{
risk society, p. 334 .
}

59 NETTO, Alamiro Velludo Salvador. Tipicidade Penal e Sociedade de Risco. São Paulo: Quartier Latin, 2006, p.28.

60 PAGLIARO, Antonio. Il Diritto Penale fra Norma e Soceità. Milano: Giuffrè Editore, 2010, p.78. 
porque merecimento e necessidade da pena descrevem seus estados sucessivos de finalidade. O primeiro, exprimindo a escolha legítima e democrática político-criminal da função retributiva do Direito Penal (por meio do processo legislativo constitucional e infraconstitucional vinculado), operando a pena aqui com função estigmatizante de reafirmação dos valores tutelados pelo sistema jurídico de cada país ${ }^{61}$; na segunda, para além da perspectiva retributivista, há a função de prevenção geral e especial da pena, pois não basta que determinado bem possua estatura tal de ser merecedor de pena, mas se afigura necessário também perquirir quais as razões de justificação e fundamentação para recorrer-se à pena para os fins de salvaguarda - preventiva e curativa - deste bem, e em que medida ela deve operar como tal. ${ }^{62}$

É certo que o Direito Penal contemporâneo, e mais especialmente a Criminologia, tem insistido na valoração de outros instrumentos de controle social e jurídico (políticas públicas, participação social, responsabilidade civil ou administrativa), eis que os tradicionais não são mais (ou igualmente) idôneos para alcançar os escopos de prevenção e a responsabilização pelo cometimento de violações de bens jurídicos tutelados pelo sistema jurídico ${ }^{63}$, mas igualmente não se pode negar que a atual Sociedade de Riscos, com os seus excessivos processos de privatização de interesses e desregulamentação estatal, vem fragilizando em muito relações interpessoais e interinstitucionais, ampliando cenários de insegurança e instabilidade da ordem pública, o que por sua vez gera reações nominadas de defesa de duvidosa licitude (por exemplo, o uso de milícias privadas e armadas para garantir segurança a determinados segmentos sociais que podem pagar por este serviço $\left.{ }^{64}\right)$.

61 Veja-se que este sistema jurídico penal, modo geral, está fundado, também, na premissa da necessidade de controlar comportamentos que poderiam, por sua violação de deveres de cuidado, criar externalidades não desejadas pela ordem (econômica, política, ideológica, religiosa) vigente, o que resgata a ideia moderna da função da norma jurídica anteriormente referida.

62 Como querem DOLCINI, Emilio \& MARINNUCCI, Giorgio. Manuale di diritto penale. Parte generale. Milano: Giuffrè, 2009, p.59.

63 A Criminologia tem tradado muito destes temas, e de forma bastante consistente, basta ver os trabalhos de: KILLIAS, M. (2006). The opening and closing of breaches: A theory on crime waves, law creation and crime prevention. European Journal of Criminology 3(1): 11-32; NELKEN, D (2009). Comparative criminal justice: Beyond ethnocentrism and relativism. European Journal of Criminology 6(4): 291-312; MOLINA, Antonio GarcíaPablos de \& GOMES, Luiz Flávio. Criminologia. São Paulo: Revista dos Tribunais, 2012; CUSSON, Maurice. Criminologia. Lisboa: Casa das Letras, 2010.

64 Neste sentido ver o texto de ALVES, José Cláudio Souza. Dos Barões ao Extermínio: Uma História da violência na Baixada Fluminense. Duque de Caxias: APPH-CLIO, 2003. Na 
Os riscos de que se está falando afetam não somente, ou fundamentalmente, bens de natureza individual (propriedade, incolumidade física, igualdade, liberdade), mas outros, de matiz coletiva ou difusa (meio ambiente, consumidor, interesses públicos indisponíveis), os quais, quando violados, implicam consequências imediatas e futuras sem precedentes e de difícil aquilatação para a Sociedade, razões pelas quais devem ser evitados com esforço e níveis de eficiência satisfatórios. Mas para tanto se faz necessário ampliar a presença do Estado Punitivo e das normativas de Direito Penal? Outros sistemas normativos e de proteção pública que não o Penal poderiam dar conta deste mister?

Tem-se que o Direito Penal pode dar contribuição importante a determinados bens jurídicos protegidos pela ordem constitucional contemporânea - no mundo e no Brasil -, não exclusiva ou fundamentalmente sob a perspectiva da dimensão punitiva segregatória individual (função liberal clássica), mas em face, por exemplo, da responsabilização patrimonial e para os fins de restrição de direitos da pessoa física e jurídica envolvida à violação destes bens.

Como diz Silva-Sanchez ${ }^{65}$, apresenta relevo a opção jurídico-política pelo Direito Penal no enfrentamento destes cenários de hipercomplexidade globalizada e mesmo de instabilidade social quando atinge bens jurídicos protegidos pela norma penal, e não apenas em face da dureza fática da sanção, a saber:

Diante do Direito Civil, de perfil predominantemente compensatório, o Direito Penal introduz sanção com força pública incontornável à persecução, valendose de instrumentos imediatos e invasivos visando à contenção, à apuração e à responsabilidade do ato criminoso ${ }^{66}$.

mesma direção o texto de CUNHA, Martin Vasques da. Como se manter íntegro em um mundo corrompido? São Paulo: Campinas, 2007.

65 SILVA SÀNCHEZ, Jesús-Maria. L'espansione del diritto penale. Aspetti della politica criminale nelle società industriali, p.185.

66 Como é o caso, no processo penal brasileiro, a possibilidade de serem adotadas algumas medidas assecuratórias à persecução penal, dentre as quais: (a) o sequestro de bens imóveis, bastando a existência de indícios veementes da proveniência ilícita dos bens, em qualquer fase do processo (arts.125, 126 e 127, do Código de Processo Penal - CPP); (b) o arresto de bens móveis suscetíveis de penhora, nos termos do art.137, do CPP; (c) a busca e apreensão para descobrir objetos necessários à prova da infração ou à defesa do réu (alínea e, do $\S 1^{\circ}$, do art. 240, do CPP), ou colher qualquer elemento de convicção para o processo (alínea $h$, do $\S 1^{\circ}$, do art.240, do CPP), dentre outros. Até no âmbito das contravenções penais (Decreto no 3.688/1941) temos penas acessórias que atingem direitos de natureza diversa da liberdade importantes à vida civil, basta ver as disposições do art. 12, 
Em face do Direito Administrativo ${ }^{67}$, o Direito Penal se afigura com maior neutralidade, notadamente diante do fenômeno político e de suas relações de Poder, em regra contaminante para os resultados que envolvem responsabilidade jurídica, assim como se apresentaria este como sendo mais imparcial a atuação da jurisdição penal, tornando mais difícil para o infrator o uso de expedientes de neutralização do juízo de desvalor das condutas levadas a cabo.

A partir destas reflexões é que se poderia pensar melhor na proposta do autor espanhol - e de tantos outros na mesma linha -, para, a partir de aí, avançarse para além dos limites tradicionais que a ciência moderna impingiu, modo geral e no que toca ao Direito e ao Direito Penal (liberal), constituindo novas responsabilidades jurídicas e penais com vocação mais rápida e intervencionista, seja para evitar os danos que os ilícitos provocam (alguns irreparáveis) na vida das pessoas e das instituições (vide os crimes de corrupção que fragilizam as instituições democráticas e representativas em todos os cantos), seja para ser eficiente na responsabilização a quem deve, tendo por foco, com exemplo, não tanto penas segregatórias de indivíduos, mas pecuniárias e restritivas de direitos (principalmente às pessoas jurídicas), fortalecendo o que se poderia nominar, no caso, de um Direito Penal da Reparação.

Há muito o que discutir ainda, mas o certo é que a ciência jurídica está perdendo campo, em certa medida, à criatividade e à imaginação dos criminosos e violadores da ordem estabelecida.

REFERÊNCIAS

AGAMBEN, Giorgio. Democracia, en que Estado? Buenos Aires: Prometeo Libros, 2014.

ALVES, José Cláudio Souza. Dos Barões ao Extermínio: Uma História da violência na Baixada Fluminense. Duque de Caxias: APPH-CLIO, 2003.

referido como tal: (i) a publicação da sentença; (ii) interdições de direitos: a incapacidade temporária para profissão ou atividade, cujo exercício dependa de habilitação especial, licença ou autorização do poder público; a suspensão dos direitos políticos.

67 Tem-se presente, todavia, que nesta Sociedade de Riscos os limites entre o Direito Administrativo e o Direito Penal tornam-se mais tênues, haja vista a existência de normas penais em branco que demandam complementação de outros instrumentos jurídicos válidos (Decretos, Portarias, Regulamentos). 
ARENDT, Hannah. A condição humana. Rio de Janeiro: Forense Universitária, 1989.

ARENDT, Hannah The Promise of Politics. New York: Schocken Books, 2005.

BAUMANN, Zygmunt. Modernidad Líquida. México: Fondo de Cultura Económica, 2008.

BECK, Urlich. La sociedade del riesgo. Hacia una nueva modernidade. Barcelona: Paidós, 1998.

BECK, Urlich Living in the world risk society. In: Economy and Society. Vol. 35. Number 3. August 2006: 329/345. Disponível em: http://www.tandfonline.com/toc/reso20/current.

BELLAMY, Foster. MAGDOFF, Fernand J. The Great Financial Crisis: Causes and Consequences. New York. Monthly Review Press, 2009.

BOURDIEU, Pierre. The Essence of Neoliberalism. In https://mondediplo. com/1998/12/08bourdieu. Acesso em: 18/01/2016.

BURKE, Roger Hopkins. An Introduction to Criminological Theory Cullumpton: Willan Publishing Campbell, 2001.

CAMPBELL, Collin. The Puzzle of Modern Consumerism. In: LEE, M. J. (Org.) The Consumer Society Reader. Oxford: Blackwell Publishers pp. 48-72, 2000.

CEPAL. América Latina Frente al Espejo: dimensiones objetivas y subjetivas de la inequidad social y el bienestar de la región. Santiago, CEPAL 2010. In: http://www.cepal.org/es/ publicaciones/2965-america-latina-frente-al-espejo-dimensiones-objetivas-subjetivas-lainequidad. Acesso em: 07/03/2016.

CUNHA, Martin Vasques da. Como se manter íntegro em um mundo corrompido? São Paulo: Campinas, 2007.

CUSSON, Maurice. Criminologia. Lisboa: Casa das Letras, 2010.

DAHL, Robert and LINDBLOM, Charles. Politics, Economy and Welfare: Planning and PoliticoEconomic Systems Resolved into Basic Social Processes. New York: Harper, 1953.

DEAN, Jodi. Enjoying Neoliberalism. Disponível em: http://www.longsunday.net/long_ sunday/files/enjoying_neo-liberalism.doc, 2005. Acesso em: 29/02/2016.

DEMICHELIS, Lelio. Società o Comunità. Roma: Carrocci Editore, 2011.

DOLCINI, Emilio \& MARINNUCCI, Giorgio. Manuale di diritto penale. Parte generale. Milano: 
Giuffrè, 2009.

ELIAS, Norbert. The Civilising Process. Oxford: Blackwell Publishing, 2003.

FARIA, José Eduardo. Direito e Globalização Econômica: implicações e perspectivas. São Paulo: Malheiros, 1996.

FERRAZ JR., Tércio Sampaio. A Ciência do Direito. São Paulo: Atlas, 1986.

FERRAZ JR., Tércio Sampaio. Introdução ao Estudo do Direito. São Paulo: Atlas, 1990.

FURLONG, Andy \& CARMEL, Fred. Young People and Social Change: Individualization and Risk in Late Modernity. Buckingham: Open University Press, 2002.

GARAPON, Antoine. I custodi del diritto, Giustizia e democrazia. Milano: Feltrinelli, 1997.

GARLAND, David. The Culture of Control: Crime and Social Order in Contemporary Society. Oxford: Oxford University Press, 2001.

GRAY, John. False Dawn: The Delusions of Global Capitalism. London: Granta, 1998.

HAYES, Mark. The Economics of Keynes: A New Guide to The General Theory. Northampton, MA, 2010.

HAYWARD, Keith J. City Limits: Crime, Consumer Culture and the Urban Experience. London: The Glasshouse Press, 2004.

HIRST, Paul. THOMPSON, Graham. Globalisation in Question. Cambridge: Polity, 2002.

HUTTON, Will. The World We're in. London: Time Warner Books, 2002.

KILLIAS, M. The opening and closing of breaches: A theory on crime waves, law creation and crime prevention. European Journal of Criminology, 2006, 3(1): 11-32.

KOTZ, Martin D. The Financial and Economic Crisis of 2008: A Systemic Crisis of Neoliberal Capitalism. In: Review of Radical Political Economics, 41: 305. 2010.

LAGOS, Marta e DAMMERT, Lucía. La Seguridad Ciudadana El problema principal de América Latina. In: http://www.latinobarometro.org/documentos/ LATBD_La_seguridad_ ciudadana.pdf. Acesso em: 08/03/2016.

LEA, John. Poverty, Crime and Politics: Frederich Engels and the Crime Question. In: LEA, John. PILLING, Geoffrey (Org.). The Condition of Britain: Essays on Frederich Engels. London: Pluto 
Books, 1996.

MACHADO NETO, A. L. Teoria da Ciência Jurídica. São Paulo: Saraiva, 1983.

MARX, Karl. O Capital. Vol.III. São Paulo: Centauro Editora, 2005.

MOLINA, Antonio García-Pablos de \& GOMES, Luiz Flávio. Criminologia. São Paulo: Revista dos Tribunais, 2012.

NELKEN, D. Comparative criminal justice: Beyond ethnocentrism and relativism. In: European Journal of Criminology, 2009, 6(4): 291-312.

NETTO, Alamiro Velludo Salvador. Tipicidade Penal e Sociedade de Risco. São Paulo: Quartier Latin, 2006.

OHMAE, Kenichi. The Borderless World: Power and Strategy in the Global Marketplace. London: Harper Collins Publishers, 1990.

PAGLIARO, Antonio. Il Diritto Penale fra Norma e Soceità. Milano: Giuffrè Editore, 2010.

PERRONE-MOISÉS, Cláudia. Direito ao Desenvolvimento e Investimento Internacional. São Paulo: Ed. Oliveira Mendes, 1998.

RORTY, Richard. Philosophy and the mirror of nature. Princeton: Princeton University Press, 1979.

RUSSELL, Bertrand. Our Knowledge of the External World. London: Oxford University Press, 1980.

SILVA SÀNCHEZ, Jesús-Maria. L'espansione del diritto penale. Aspetti della politica criminale nelle società industriali. Milano: Giuffrè-Quaderni di diritto penale comparato internazionale ed europeo, 2004.

STEGMÜLLER, Wolfang. A Filosofia Contemporânea. São Paulo: Edusp, 1977.

THORSTENSEN, Vera. OMC - Organização Mundial do Comércio: as regras do comércio internacional e a Nova Rodada de Negociações Multilaterais. São Paulo: Aduaneiras, 2001.

UNODC. World Report on Homicides. Disponível em: https://www.unodc.org/gsh/. Acesso em: 07/03/2016.

VEBLEN, Thorstein. Conspicuous Consumption. In: Lee, M J (Org.) The Consumer Society Reader. Oxford: Blackwell Publishers, 2000. 
VIEHWEG, Theodor. Topica y jurisprudencia. Madrid: Taurus, 1984.

WARAT, Luis Alberto. Senso Comum Teórico: as vozes incógnitas das verdades jurídicas. In: Introdução Geral ao Direito. Porto Alegre: Fabris, 1994.

WARAT, Luis Alberto. Sobre la Dogmática Jurídica. In: Revista Seqüência, $n^{\circ} 02$, ano $1,2^{\circ}$ Semestre de 1980, Florianópolis, 1980, pp.33/55.

Recebido em: abr/2016

Aprovado em: mai/2016 